\title{
Erratum to: Estimating the crop response to fertilizer nitrogen residues in long-continued field experiments
}

\author{
J. Petersen • I. K. Thomsen • L. Mattsson • \\ E. M. Hansen • B. T. Christensen
}

Published online: 19 April 2012

(C) Springer Science+Business Media B.V. 2012

\section{Erratum to: Nutr Cycl Agroecosyst \\ DOI 10.1007/s10705-012-9482-4}

In the original publication, the values in Table 7 under the column "Parameters and effects" were incorrectly published. The revised version of Table 7 is given.

The online version of the original article can be found under doi:10.1007/s10705-012-9482-4.

J. Petersen $(\varangle) \cdot$ I. K. Thomsen · E. M. Hansen

B. T. Christensen

Department of Agroecology, Aarhus University, PO Box 50, 8830 Tjele, Denmark

e-mail: JEPE@DMU.dk

Present Address:

J. Petersen

Department of Bioscience, Aarhus University,

PO Box 314, 8860 Silkeborg, Denmark

L. Mattsson

Department of Soil and Environment, SLU,

Swedish University of Agricultural Sciences,

PO Box 7014, 75007 Uppsala, Sweden 


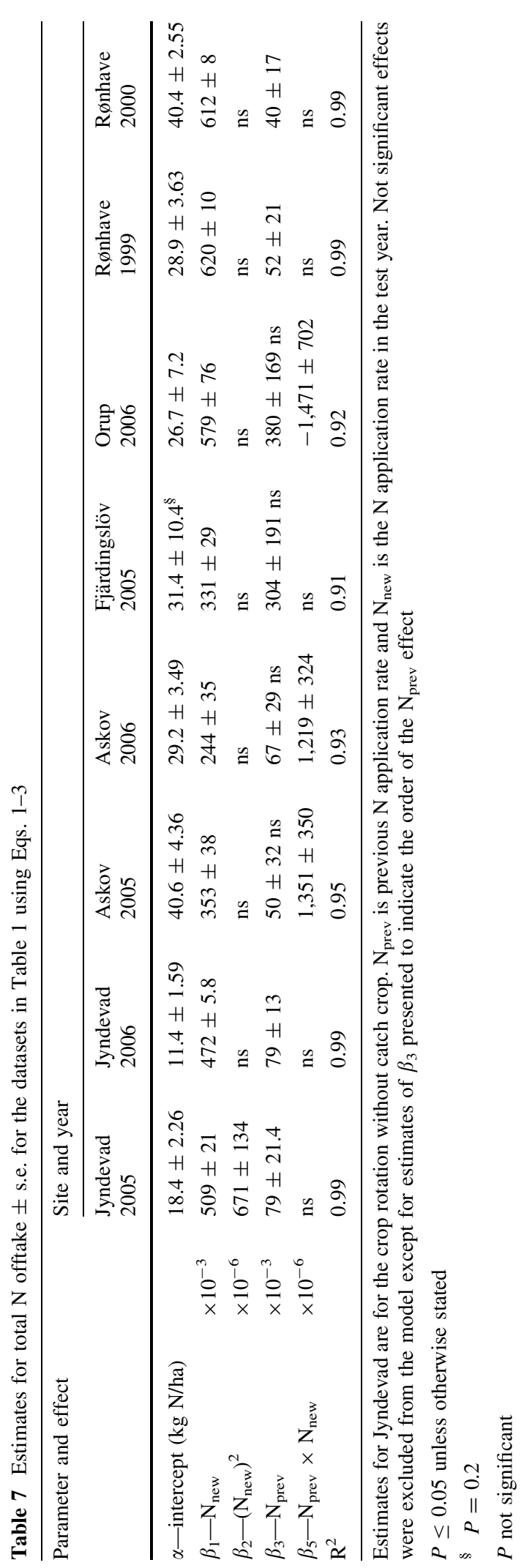

